\title{
De la peste pharaonique à la cyber épidémie de fièvre hémorragique à virus Ebola
}

\author{
F. Klotz \\ (C) Lavoisier SAS 2014
}

Communiqué «Un jeune guinéen de 20 ans a présenté il y a une semaine une hyperthermie à $40^{\circ} \mathrm{c}$ avec céphalées, myalgies, maux de gorge. Il est rentré à l'hôpital dans le service de pathologie infectieuse, en secteur d'isolement, il y a quatre jours avec des vomissements hémorragiques et une diarrhée sanglante. Il est entré dans le coma hier avec un tableau d'insuffisance hépatique et rénale et est décédé ce matin! »

Depuis que les hommes vivent en communauté, ils échangent des agents pathogènes! Les contingences climatiques, socio-économiques ou militaires sont des facteurs favorisants. Les invasions, les migrations volontaires ou non, les voyages sont des facteurs déterminants et amplificateurs fragilisant les écosystèmes et modifiant les conditions d'hygiène de salubrité et d'immunité.

Les épidémies ont accompagné l'histoire de l'humanité depuis des milliers d'années. Il est toujours intéressant de s'arrêter quelques instants et de regarder dans le kaléidoscope de l'histoire de celles-ci.

La terrible peste a sévit dans le monde depuis l'Egypte pharaonique et jusqu'au $\mathrm{XX}^{\mathrm{e}}$ siècle. Les téléspectateurs friands d'informations à sensations savent-ils que la grande peste de Marseille fit 100000 morts en 1720 et probablement plus de 10 millions de morts en Inde dans la première moitié du XX $\mathrm{X}^{\mathrm{e}}$ siècle !

Le choléra a également accompagné l'humanité jusqu'à nos jours avec ses sept pandémies ravageant les populations fragilisées réfugiées ou victimes de catastrophes naturelles comme en Haïti en 2010 où il fut responsable de 1500 morts en plus des dizaines de milliers de victimes du tremblement de terre.

La variole a fait des hécatombes au cours des siècles. Responsable de milliers de morts, elle n'a pas épargné les hommes célèbres tuant entre autres deux empereurs incas, décimant la famille de Louis XIV et Louis XV lui-même, atteignant Staline. La dernière épidémie en France date de 1954 où un voyageur venant d'Indochine fut à l'origine de 73 cas à Vannes en Bretagne avec 16 morts.

L'épidémie actuelle de fièvre à virus Ebola en Afrique noire est inquiétante, mais elle prend un aspect très particu-

F. Klotz $(\bowtie)$

e-mail : fklotz2008@yahoo.fr lier. Il y a quelques décennies, elle n'aurait pas dépassé le continent africain. Il y a 40 ans lors des premiers cas dans le village d'Ebola, avant internet et la télévision mondialisée peu de personnes en avaient entendu parler.

Les nouvelles sont actuellement diffusées dans le monde entier à l'instant $\mathrm{T}$. Le monde occidental est concerné et inquiété car il se croyait à l'abri de ces fléaux tropicaux venant de la forêt profonde, mais les moyens de transport aériens véhiculent les hommes avec leurs agents pathogènes et en particulier ces filovirus.

La mobilisation mondiale pour juguler ce fléau viral sournois et mortel s'amplifie. La prise de conscience de la faiblesse des systèmes de santé de certains pays africains est prégnante. La révélation des difficultés à modifier les traditions et les coutumes, facteurs de transmission du virus est une réalité. Les liquides biologiques sont porteurs du virus et redoutablement contaminants, les malades ne peuvent rester dans leur maison ou dans leur case, mais isolés dans des lieux dédiés. L'hygiène doit être rigoureuse et les rites funéraires interdits. Le matériel à usage unique et les protections vestimentaires du personnel soignant doivent être généralisés jusqu'au plus petit poste de santé ; souhait utopique!

L'argent ne suffit pas pour faire ces grands pas de modifications de l'éducation, de la culture, de la technologie. Il faut des hommes et des femmes désintéressés et volontaires. Il faut du temps. Durant cette période organisationnelle incompressible, le virus continue à se propager, à voyager, à pointer son sinistre visage jusque dans les capitales européennes ou américaines.

Le virus Ebola est, comme beaucoup d'autres agents pathogènes, responsable d'épidémie chez l'homme, de provenance animale. Il s'est transmis à l'homme dans la forêt africaine, à partir du contact et de la consommation d'animaux sauvages, eux-même probablement contaminés par des chauves-souris. La chaine épidémiologique garde quelques mystères sur l'origine de ce filovirus, mais est bien démembrée dans la traçabilité de sa transmission.

Ces agents pathogènes viennent des zones défavorisées de notre planète.

Continuons à nous mobiliser en Afrique et dans le monde pour éteindre cette épidémie traitre et mortelle, mais n'oublions pas la très longue et très meurtrière histoire des épidémies. 